\title{
Dietary considerations for patients undergoing orthodontic treatment: A review
}

\author{
Parvinder Kaur ${ }^{1}$, Rajiv Ahluwalia ${ }^{2, *}$, Deepa Verma ${ }^{3}$, Himanshu Garg $^{4}$, Kunal Sharma $^{5}$ \\ ${ }^{1}$ Reader, ${ }^{2}$ Professor \& Head, ${ }^{3}$ Professor,, 4 Post Graduate Student, Dept. of Orthodontics \& Dentofacial, Orthopedics, Santosh \\ Dental College and hospital, Ghaziabad, Uttar Pradesh, India.
}

*Corresponding Author:

Email: drrajivahluwalia@gmail.com

\begin{abstract}
Proper diet and nutrition are important factors which influence the general health, growth and tissue tolerance of orthodontic patients on many levels. While orthodontist will rarely see frank manifestations of nutritional deficiencies, it should be recognized that suboptimal levels of certain nutrients are common and have an effect on the biological response of the tissues influenced by orthodontic treatment. Orthodontic treatment involves the use of attachments and forces element that can negatively affect the dietary intake compromising the nutrition of the patient. On the other hand for effective orthodontic treatment a balanced diet is required. Thus it becomes a vicious cycle. Most orthodontic patients are in the growing age. Balanced diet is essential for them. However some food in its hard and crunchy form may be avoidable during orthodontic treatment. Therefore alternate methods of intake of such food item is essential. This article highlights the importance of dietary considerations for orthodontic treatment and also how the patient can alter their dietary habits without compromising on nutrition.
\end{abstract}

Keywords: Diet, Food, Orthodontic patients, Nutrition, Fruits.

\section{Introduction}

A balanced diet contains adequate amount of all the necessary nutrients required for normal growth and activity. ${ }^{1}$ It also provides natural disease prevention, weight control, proper sleep and it is also important because it enables to maintain daily nutritional needs. Orthodontic treatment also affects a patient's diet and overall health. $^{2}$

Orthodontics is a field where most patients are adolescents who are still in their growing phase. Adolescence is a period of profound physiological and psychological changes and this period is also associated with altered nutritional needs. ${ }^{3}$ There is a very high demand of proper nutrition in adolescents because of the rapid growth and development as well as the emotional stress of puberty. Hence the importance of well-balanced diet is paramount. ${ }^{4}$ During orthodontic treatment there is requirement of modified diet, but deficient and poor nutrient intake should be avoided. ${ }^{4}$ Orthodontic treatment leads to discomfort and functional limitations due to pressure sensitivity to the teeth. ${ }^{5-8}$ Because of the pressure sensitivity of teeth in orthodontic patients, there is difficulty in eating hard food so there is a tendency for soft food to be consumed. This lead to elimination of solid foods such as raw vegetables and fresh fruits ${ }^{9-12}$ and stringy foods such as meat and dry foods such as breads. ${ }^{13}$ from the diet.

When a patient undergoes orthodontic treatment, the orthodontist takes care of the technical aspect of the treatment, but patient's compliance is also a major factor in the success of orthodontic treatment. Maintaining good oral hygiene is one of the most important factors of orthodontic treatment and it depends primarily upon the dietary habits of the patient.
So Diet counselling in orthodontic patients makes them understand what to eat and what not during orthodontic treatment. This article presents an overview of the dietary consideration in orthodontic patients.

Diet counselling in orthodontic patients: Every orthodontic patient is subjected to a number of challenges that require a certain level of host immunity and response, which is partially dependent on nutritional status. These challenges include the requirement for tissue response to orthodontic forces in periodontal ligaments and bone. ${ }^{14}$ Diet counselling includes evaluation of patient diet by taking patient diet pattern history, suggestions to modify meal by restriction of certain foods and reliable methods and options of alternative foods given to them to maintain the nutritional status.

Foods which should be avoided and alternative method to consume them during orthodontic treatment

1. When fixed appliances are bonded to teeth, it is important to completely eliminate certain foods from orthodontic patient's diet or they could be consumed in different ways so breaking or loosening of appliance can be prevented. (Table 1) Foods which should be avoided during orthodontic treatment include hard, crunchy and sticky food. Sticky foods should be strictly avoided during an orthodontic treatment since they can get stuck between the brackets or orthodontic appliance and there is a risk of damaging the appliances and/or the wire while trying to clean out the sticky food.

2. Certain habits should also be avoided which include

a) Chewing on pencils, pens or any other hard objects. 
b) Biting nails with teeth.

c) Never try to open a plastic packaging, soft or hard, with your teeth.

There is also need of avoiding following food biting with front teeth during orthodontic treatment.

a) Toasted bread

b) Pizza crust not softened by toppings

c) Health bars

\section{d) Kachori}

Alternative foods which could be consumed during orthodontic treatment to maintain nutritional status

It is very important to understand the alternative foods which can be consumed to ensure good health and avoid any undue breakages or problems during the treatment. (Table 2)

Table 1: Foods to avoid and alternative method to consume them during orthodontic treatment

\begin{tabular}{|c|c|}
\hline S. No. & Foods to avoid and alternative method to consume \\
\hline 1. & $\begin{array}{l}\text { Hard and Crunchy Food } \\
\text { 1. Corn on the cob } \\
\text { 2. Crusty bread, tandoor naan or paratha } \\
\text { 3. Thick chips and hard crackers. One can consume "normal" potato chips but they } \\
\text { should be soft before chewing them. } \\
\text { 4. Hard candies such as lollipops, cough lozenges } \\
\text { 5. Very hard nuts, such as whole almonds, peanuts, walnuts etc. Whenever possible, } \\
\text { these can be eaten crushed. } \\
\text { 6. Popcorn, the hard and unpopped grains of corn } \\
\text { 7. Raw vegetables (carrot, radish, etc.). However, the patient can cook them until } \\
\text { tender or eat them raw but grated. } \\
\text { 8. Whole raw fruits, such as apples, pears, etc and fruits that are not quite ripe. Care } \\
\text { should be taken to cut the fruits up into small pieces and remove all seeds before } \\
\text { consumption. } \\
\text { 9. French fries that are small and crunchy. } \\
\text { 10. Certain types of cereals can be particularly hard and crunchy when they are dry. It } \\
\text { is then forbidden to eat them without softening them with milk or any other liquid } \\
\text { beforehand. } \\
\text { 11. Only boneless and soft meat should be consumed }\end{array}$ \\
\hline 2. & $\begin{array}{l}\text { Sticky Foods } \\
\text { 1. Jellied candies, sticky caramel, éclair, toffees, fruit roll-ups, big marshmallows and } \\
\text { any other candy that can stick to the appliances when they soften. } \\
\text { 2. Avoid any type of chewing gum, without exception. If the patient wishes to } \\
\text { freshen up breath after a meal, they can brush their teeth or use dissolving breath } \\
\text { mint strips that melt easily on the tongue. However, these must not be over used } \\
\text { since they can irritate their gums. Alternatively, peppermint sprays or mouthwash } \\
\text { can also be used. }\end{array}$ \\
\hline
\end{tabular}

Table 2: Alternative foods which could be consumed during orthodontic treatment

\begin{tabular}{|l|l|}
\hline \multicolumn{2}{|c|}{ Alternative foods which could be consumed during orthodontic treatment } \\
\hline Vegetarian & 12. nutritional supplements \\
1. Dairy - yogurt, pudding, soft cheese & 13. Mashed banana \\
2. Steamed veggies & 14. Light crackers or cookies \\
3. Soft fruits - melons, grapes, oranges, kiwi & 15. Soft-cooked rice \\
4. Mashed boiled potatoes and cooked vegetables & 16. Soft-cooked beans \\
5. Oatmeal & 17. Soft breads and chapatis \\
6. Pancakes, slices of bread and French toast & Non-vegetarian \\
7. Soups & 1. Eggs in all forms: scrambled eggs, \\
8. Cooked pasta (spaghetti, macaroni, etc.) & poached eggs and omelets \\
9. Cakes, soft ice cream (without a cone) & 2. Cooked boneless fish \\
10. Yogurt, curd, kheer, custard & 3. Boneless meat \\
11. Milkshakes, smoothies, liquid & 4. Seafood - tuna, salmon, fish without \\
\hline \multicolumn{2}{|l}{ bones, etc. } \\
\hline
\end{tabular}




\section{Conclusion}

To optimize patient's experience and to reduce discomfort during orthodontic treatment, it is beneficial to provide dietary guidance to orthodontic patients in choosing their diet. Patients undergoing orthodontic treatment should be encouraged to consume solid foods like fruits, vegetables, grains and cereals and soft food stuffs according to the manner advised and prescribed in the article so that all the components of adequate balanced diet including carbohydrates, fatty acids, proteins, vitamins and minerals could be maintained. This will ensure a pleasant experience for the patient and also results in reduced treatment time and decreased chairside time for each visit.

\section{References}

1. Southon S, Wright AJ, Finglas PM, Bailey AL, Belsten JL. Micronutrient intake and psychological performance of schoolchildren: consideration of the value of calculated nutrient intakes for the assessment of micronutrient status in children. Proc Nutr Soc. 1992;51(3):315-24.

2. Luke B. Principles of Nutrition and Diet Therapy. Little Brown and company. 1984:3:816.

3. Heald FP, Gong EJ. Diet, nutrition, and adolescence. In: Shils ME, Olson JA, Shike M, Ross AC, eds. Modern nutrition in health and disease. $9^{\text {th }} \mathrm{ed}$. Baltimore. Lippincott Williams and Wilkins. 1999;855-67.

4. Hickory W, Nanda R. Nutritional considerations in orthodontics. Dent Clin North Am. 1981;25:195-201.

5. Utomi IL. Challenges and motivating factors of treatment among orthodontic patients in Lagos, Nigeria. Afr J Med Med Sci. 2007;36:31-36.
6. Bernabé E, Sheiham A, de Oliviera CM. Impacts on daily performances related to wearing orthodontic appliances. Angle Orthod. 2008;78:482-86.

7. Sergl HG, Klages U, Zentner A. Pain and discomfort during orthodontic treatment: causative factors and effects on compliance. Am J Orthod Dentofacial Orthop. 1998;114:684-91.

8. Sergl HG, Klages U, Zentner A. Functional and social discomfort during orthodontic treatment-effects on compliance and prediction of patients' adaptation by personality variables. Eur J Orthod. 2000;22:307-15.

9. Wayler AH, Kapur KK, Feldman RS, Chauncey HH. Effects of age and dentition status on measures of food acceptability. J Gerontol. 1982;37:294-99.

10. Brodeur JM, Laurin D, Vallee R, Lachapelle D. Nutrient intake and gastrointestinal disorders related to masticatory performance in the edentulous elderly. $J$ Prosthet Dent. 1993;70:468-73.

11. Joshipura KJ, Willett WC, Douglass CW. The impact of edentulousness on food and nutrient intake. J Am Dent Assoc. 1996;127:459-67.

12. Garcia RI, Perlmuter LC, Chauncey HH. Effects of dentition status and personality on masticatory performance and food acceptability. Dysphagia. 1989;4:121-16.

13. Hildebrandt GH, Loesche WJ, Lin CF, Bretz WA. Comparison of the number and type of dental functional units in geriatric populations with diverse medical backgrounds. J Prosthet Dent. 1995;73:253-61.

14. Ferguson HW, Alfano MC. Controversies, perspectives, and clinical implications of nutrition in periodontal disease. Dent Clin North Am. 1976;20:519-48. 